\title{
Occupational Radiation Exposure during Pregnancy: A Personal Experience
}

\author{
Sarika Prashar
}

\begin{abstract}
Introduction: The maximum permissible dose limit to an occupational radiation worker has been universally fixed at $20.0 \mathrm{mSv}$ per annum. However, this limit in the case of a pregnant radiation worker is set at $1.0 \mathrm{mSv}$ as the developing embryo/fetus is considered as a member of the general public. Thus, a female radiation worker during her pregnancy encounters a typical situation where she has to keep a balance between the prescribed radiation dose restrictions and the professional commitment.

Materials and methods: In the present article, the radiological safety officer describes her own experience and the radiation risk to the fetus during the entire period of pregnancy, using thermoluminescent dosimeters (TLD) badges and digital pocket monitors.

Results: In the present study, the total radiation doses received during the two pregnancy episodes (as recorded by TLDs and digital pocket monitors) on the surface of abdomen were $550.0 \mu \mathrm{Sv}$ and $400 \mu \mathrm{Sv}$, and $98.0 \mu \mathrm{Sv}$ and $88.0 \mu \mathrm{Sv}$, respectively.

Conclusion: Practically, pregnant workers can work safely by following appropriate shielding and radiation safety practices.

Keywords: Fetal absorbed dose, Nuclear medicine, Pregnancy, Radiation exposure.

Journal of Postgraduate Medicine Education and Research (2020): 10.5005/jp-journals-10028-1347
\end{abstract}

\section{INTRODUCTION}

Every living being is exposed to radiations every day, either from low-level radiation found in food, soil, building materials, air, and/ or from outer space. The average natural background radiation exposure is about 2.0-3.0 mSv per year. A radiation worker can get a radiation exposure dose of $20.0 \mathrm{mSv}$ each year above this background level. ${ }^{1}$ However, the limit for a pregnant radiation worker is set at $1.0 \mathrm{mSv}$ to the embryo/fetus during the remaining period of pregnancy after the declaration of her pregnancy. Thus, a pregnant radiation worker particularly presents a challenging situation. This article presents the personal experience of a nuclear medicine radiation safety officer (RSO) during her pregnancy which might act a guide to such workers to follow good practice of radiation safety to keep the dose to the fetus within the prescribed limit without compromising the professional commitment.

\section{Radiation Exposure}

The radiation workers in a clinical nuclear medicine facility are occupationally exposed to different nuclear radiations ( $\alpha, \beta, \gamma$, and positrons). The exposure to the workers is generally received during the preparations of radio-pharmaceuticals, patients' injections, and from injected patients during positioning and imaging. A nuclear medicine department has four designated areas, viz. restricted, controlled, supervised, and unrestricted areas. The radiation exposure levels vary in these different areas. An access to the restricted zone is limited from the viewpoint of radiation protection, and this area is not accessible to all radiation workers and the general public. Restricted zone includes controlled area with limited access such as cyclotron room and radionuclide therapy wards. Restricted zone also includes supervised area which is accessible to all the radiation workers but not the general public such as hot lab, PET radiopharmacy room, gamma imaging room, PET scanner, and clean quality control room. Unrestricted zone includes all other rooms and offices which are occupied by
Department of Nuclear Medicine, Postgraduate Institute of Medical Education and Research, Chandigarh, India

Corresponding Author: Sarika Prashar, Department of Nuclear Medicine, Postgraduate Institute of Medical Education and Research, Chandigarh, India, Phone: +91 9876120142, e-mail: sarika2j@gmail. com

How to cite this article: Prashar S. Occupational Radiation Exposure during Pregnancy: A Personal Experience. J Postgrad Med Edu Res 2020;54(1):5-7.

Source of support: Nil

Conflict of interest: None

the individuals such as patients, visitors, and employees who do not directly work with the radiation sources. ${ }^{2}$ Figure 1 shows the typical division of different radiation zones in nuclear medicine department at PGIMER, Chandigarh.

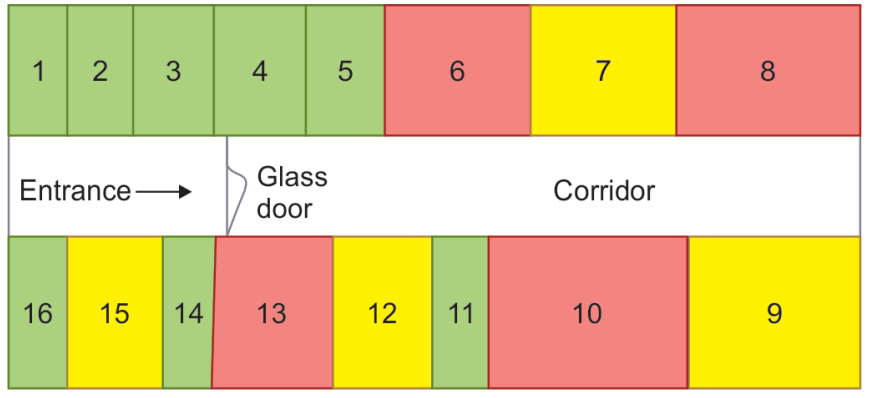

Fig. 1: Outline of various radiation zones in the department. Room nos. $1-5,11,14$, and 16 shown in green color are unrestricted areas with minimal or no radiation exposure. Room nos. 7, 9, 12, and 15 (shown in yellow) are supervised areas where radiation exposure ranges from 0.7 to $1.5 \mu \mathrm{Sv} /$ hour. Room nos. $6,8,10$, and 13 (shown in red color) are controlled areas with radiation levels between $2 \mu \mathrm{Sv} / \mathrm{hour}$ and $15.0 \mu \mathrm{Sv} /$ hour 
Table 1: Deterministic effects at different stages of gestation and the threshold doses

\begin{tabular}{lll}
\hline Radiation effects & $\begin{array}{l}\text { Gestation time } \\
\text { (weeks) }\end{array}$ & $\begin{array}{l}\text { Threshold dose } \\
\text { (mGy) }\end{array}$ \\
\hline Embryonic death & $3-4$ & $100-200$ \\
Major malformations & $4-8$ & $250-500$ \\
Growth retardation & $4-8$ & $250-500$ \\
Severe mental retardation & $8-15$ & $50-500$ \\
Microcephaly & $8-15$ & $>20,000$ \\
IQ reduction & $16-25$ & $>100$ \\
Neonatal death & $26-38$ & $>500$ \\
\hline
\end{tabular}

The monitoring of radiation exposure to the radiation workers is a mandatory requirement. Each radiation worker in a nuclear medicine setting is required to wear two thermo-luminescent dosimeters (TLD) that is one as a chest badge and the second one as a wrist badge. The declaration of pregnancy by a female radiation worker is obligatory. Once the pregnancy status is confirmed, she is required to wear an additional badge at the level of abdomen during the entire pregnancy period to monitor the total exposure dose to the embryo/fetus. The TLD badges are changed every 3 months and sent to the approved agencies for radiation absorbed dose readings. The designated RSO in each department keeps the records of absorbed doses received by an individual radiation worker. The RSO ensures that the doses do not exceed the regulatory limits prescribed for radiation workers in general and pregnant workers in particular.

\section{Radiation Risks}

Risks associated with radiation exposure fall into two categories, stochastic risks and deterministic risks. The probability of stochastic effects increases with the dose while the deterministic effects (also called as nonstochastic effects) occur above a threshold dose. Risks associated with the embryo/fetus are divided into preconception and perinatal risks. The radiation exposure in the preconception period may lead to sterility or genetic mutations leading to hereditary effects. As per the BEIR V report, a temporary sterility results from a single acute exposure of 0.65-1.5 Gy and permanent sterility in adult ovary can occur at an acute radiation dose of 2.5-6.0 Gy. ${ }^{3}$ The long-term and repeated exposure of more than 0.2 Gy may lead to permanent sterility in female reproductive organs. These doses are well above the typical lifetime exposure in any nuclear medicine procedures. ${ }^{4}$ Thus, for the female radiation worker in the nuclear medicine department, the risks of sterility or hereditary effects are minimal. Most perinatal risks are nonstochastic in nature and very much depend on the stage of gestation. Table 1 summarizes the deterministic effects and threshold doses at different gestational weeks.

Radiation exposure during the period before the embryo is implanted may increase the radiation risk, but if the embryo is able to survive and implant, then it is expected to grow normally. The actual risks of the miscarriage at this stage are not known, as most of the times, the female worker is unaware of her pregnancy in the initial 1-3 weeks. At the time of organogenesis (from 3 weeks till 8 weeks), the effects of radiation exposure above the threshold level can result in the major malformations and growth retardation. The primary risks between 8 weeks and 15 weeks of the gestation are severe mental retardation and growth retardation. Risk of decrease in intelligence quotient and mental disability is observed in 16 weeks and above, if mother is exposed to high radiation doses. ${ }^{4}$

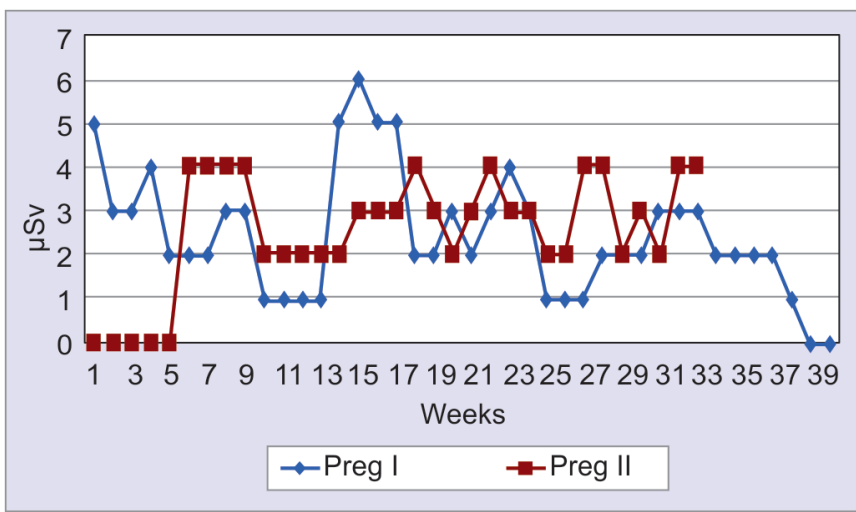

Fig. 2: Radiation exposure in $\mu \mathrm{Sv}$ during the entire pregnancy period of 40 weeks

The risk of developing cancer after prenatal radiation exposure does not hold a threshold and thus is a stochastic risk. The carcinogenic risk has a linear relationship with the radiation dose, stating that even a small perinatal radiation exposure can potentially increase the risk of cancer occurrence. ${ }^{5-7}$ The estimated absolute risk is about $6.0 \%$ per Gy of the fetal exposure. ${ }^{8}$

Practically, it is extremely rare to encounter such an incident in view of the strict practice and regulations followed by the highly trained professionals and periodic surveillance of the nuclear medicine facilities by the regulatory authorities. As per the guidelines, the permissible radiation dose for the entire pregnancy is $1.0 \mathrm{mSv}$ or approximately $25 \mu \mathrm{Sv} /$ week (1000 $\mu \mathrm{Sv} / 40$ weeks). ${ }^{1,9}$

In the present study, the total radiation doses received during the first and second pregnancy (as recorded by TLDs) on the surface of abdomen were $550.0 \mu \mathrm{Sv}$ and $400 \mu \mathrm{Sv}$, respectively. The results of the radiation exposure (in $\mu \mathrm{Sv}$ ) during two pregnancies ( 40 weeks each) in the same radiation worker are presented in Figure 2. However, the radiation exposures as read by digital monitor (RAD $60 S$, Rados Technology, Finland) over 2 pregnancies were 98.0 and $88.0 \mu \mathrm{Sv}$, respectively. Therefore, the radiation exposures by digital monitor are underestimated. It is thus observed that TLD provides more realistic absorbed dose measurements received by the fetus/ embryo and were well within the permissible limits. It has been previously reported by Sylvain et al. that a nuclear medicine worker performing majority of the routine duties in different locations typically receives radiation doses that are below $10.0 \mu$ Sv per day. ${ }^{10}$ The average dose received per procedure can be further reduced with training and use of shielding material. ${ }^{11}$

\section{Recommendations to Reduce Radiation Exposure Dose}

Radiation doses to the radiation workers should be kept ALARA (as low as reasonably achievable), and this principle (ALARA) is practiced as a guide for dose reduction to occupational workers. Although the radiation dose limits specified by AERB are legal limits that must not be exceeded at any time, these are not the threshold values. The basic principles of radiation protection includes time, distance, and shielding. Decreasing the time of exposure and increasing the distance from the radioactive source can drastically reduce the radiation exposure to the worker. And further, a proper use of shielding is very effective in minimizing the radiation dose to a worker. Although wearing a lead apron is generally not recommended in a pregnant nuclear medicine worker, she should consult a RSO if additional protection is to be provided by a lead 
apron. ${ }^{12,13}$ And duty roster modifications of a pregnant worker shifting her to low radiation dose areas may also be considered as an alternative approach for reducing the radiation dose exposures in pregnant workers.

In the present case scenario, the pregnant worker completely avoided the duties in the restricted zone like cyclotron room and radiotherapy ward and some controlled areas like PET radiopharmacy, PET/CT scanner room and SPECT/CT room. Her duties were further modified and she was told to avoid some supervised areas like hot lab for long durations and gamma imaging room on the day of scanning of radioiodine therapy patients. However, she performed duties for 40 hours per week with the job modifications. Till the full term of the pregnancy, she spent on an average 14-15 hours in an in vitro lab, 6 hours in the counting room, 6 hours in hot lab, and remaining 14 hours in the single head gamma imaging room. ICRP recommends not to terminate the pregnancy if fetal radiation exposure is less than $100 \mathrm{mGy} .{ }^{9}$ If the fetal dose is between 100 and $500 \mathrm{mGy}$, the decision lies on the female worker and RSO based on the circumstances. The termination is justified if the fetal radiation dose is more than $500 \mathrm{mGy}$, as significant fetal damage may happen. ${ }^{14,15}$

\section{Conclusion}

In the past few decades, the involvement of females in the nuclear medicine fraternity has increased, and thus, understanding radiation exposure and risks is important part of the job profile. The general notion that it is not safe for pregnant workers to work in the nuclear medicine and radiological center is thus only a myth. Practically, pregnant workers can work safely by following appropriate shielding and radiation safety practices.

\section{References}

1. AERB Directive No. 01/2011-the dose limits for exposures from ionizing radiations for workers and the members of the public.
2. Cherry SR, Phelps ME, Sorenson JA. Internal radiation dosimetry. In: Physics in Nuclear Medicine, 4th ed., Philadelphia, PA:Saunders; 2012. pp. 407-433.

3. BEIR (Committee on the Biological Effects of lonizing Radiations). Health effects of exposure to low levels of ionizing radiation. Washing-ton, DC: National Academy Press; 1990.

4. McCollough $\mathrm{CH}$, Schueler BA, Atwell TD, et al. Radiation exposure and pregnancy: when should we be concerned? Radiographics 2007;27(4):909-917. DOI: 10.1148/rg.274065149.

5. Preston DL, Sokolnikov ME, Krestinina LY, et al. Estimates of radiation effects on cancer risks in the mayak worker, Techa river and atomic bomb survivor studies. Radiat Prot Dosimetry 2017;173(1-3):26-31. DOI: 10.1093/rpd/ncw316.

6. Krestinina LY, Kharyuzov YE, Epiphanova SB, et al. Cancer incidence after in utero exposure to ionizing radiation in techa river residents. Radiat Res 2017;188(3):314-324. DOI: 10.1667/RR14695.1.

7. Brent RL. Carcinogenic risks of prenatal ionizing radiation. Semin Fetal Neonatal Med 2014;19(3):203-213. DOI: 10.1016/j.siny.2013.11.009.

8. Shaw P, Duncan A, Vouyouka A, et al. Radiation exposure and pregnancy. J Vasc Surg 2011;53(Suppl):28S-34S. DOI: 10.1016/ j.jvs.2010.05.140.

9. ICRP. Pregnancy and medical radiation. ICRP Publication 84. Ann ICRP 2000;30(1):1-43. DOI: 10.1016/S0146-6453(00)00024-5.

10. Sylvain I, Bok B. Radiation exposure in nuclear medicine: realtime measurement. Brazilian Archives of Biology and Technology 2002;45:111-114. DOI: 10.1590/S1516-89132002000500015.

11. Smart R. Task-specific monitoring of nuclear medicine technologists' radiation exposure. Radiat Prot Dosimetry 2004;109(3):201-209. DOI: 10.1093/rpd/nch301.

12. Osei EK, Kotre CJ. Equivalent dose to the fetus from occupational exposure of pregnant staff in diagnostic radiology. $\mathrm{Br} J$ Radiol 2001;74(883):629-637. DOI: 10.1259/bjr.74.883.740629.

13. Sabino J, Grauer JN. Pregnancy and low back pain. Curr Rev Musculoskelet Med 2008;1:137-141. DOI: 10.1007/s12178-008-9021-8.

14. Brent RL. Protection of the gametes embryo/fetus from prenatal radiation exposure. Health Phys 2015;108(2):242-274. DOI: 10.1097/ HP.0000000000000235.

15. Russell JR, Stabin MG, Sparks RB, et al. Radiation absorbed dose to fetus. Health Phys 1997;73:756-769. DOI: 10.1097/00004032199711000-00003. 